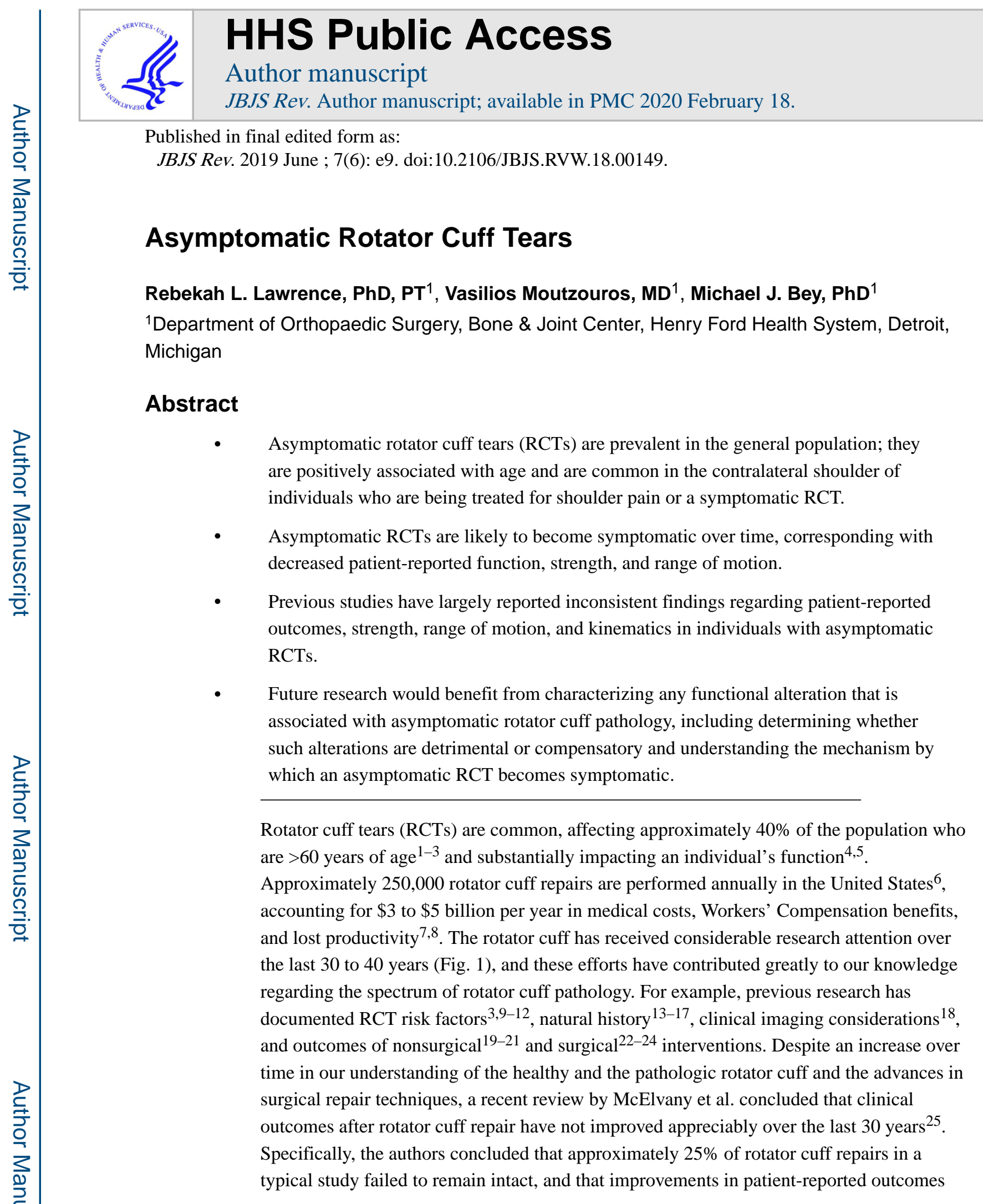

R.L. Lawrence: rlawren2@hfhs.org.

Investigation performed at the Department of Orthopaedic Surgery, Bone \& Joint Center, Henry Ford Health System, Detroit, Michigan

The Disclosure of Potential Conflicts of Interest forms are provided with the online version of the article (http://links.lww.com/ JBJSREV/A444). 
were $<75 \%$ of the possible maximum improvement ${ }^{25}$. These findings indicate that, despite the substantial volume of research that has focused on rotator cuff pathology, postsurgical outcomes following rotator cuff repair remain suboptimal.

In addition to suboptimal clinical outcomes, the etiology of RCTs is still not fully understood. One issue that confounds our understanding of rotator cuff pathology is that chronic RCTs initially may be asymptomatic and may remain asymptomatic for an unknown and likely highly variable period of time. Furthermore, clinical evidence suggests that individuals with an asymptomatic RCT may be capable of a high level of shoulder function $^{14-16,20,26-28}$. Therefore, if outcomes after surgical repair have not improved markedly over the last 30 or more years and a high level of shoulder function can be achieved in spite of an asymptomatic RCT, then perhaps an alternative strategy for addressing this long-standing clinical problem may involve (1) identifying rotator cuff pathology when an individual is still asymptomatic and has acceptable shoulder function and (2) intervening with exercises that are designed to ensure that the RCT remains asymptomatic while maintaining or improving shoulder function. Unfortunately, far less is known about asymptomatic RCTs compared with symptomatic tears. Thus, the primary objective of this article is to summarize what is currently known about asymptomatic RCTs, with specific focus on the prevalence, patient-reported outcomes, shoulder function, and natural history. Opportunities for future research also are suggested.

\section{Prevalence of Asymptomatic RCTs}

The prevalence of asymptomatic partial-thickness and full-thickness RCTs has been reported to range from $8 \%$ to $40 \%$ and from $0 \%$ to $46 \%$, respectively $1,10,26,28-37$ (Table I). In general, the prevalence of asymptomatic RCTs increaseswithage ${ }^{1,26,28,31,32,34,35,38,39}$, and individuals with an asymptomatic full-thickness RCT tend to be older than those with a partial-thickness $\mathrm{RCT}^{31,34,40}$. The wide range of reported prevalence is likely due to several factors. First, the characteristics of the subject populations from which the data were acquired certainly influenced the reported prevalence rate. For example, some studies reported rates of asymptomatic RCTs in individuals with a contralateral symptomatic ${ }^{10,37,40}$ or postsurgical shoulder ${ }^{33}$. Not surprisingly, the prevalence of an asymptomatic RCT in these populations is much higher than in the general population. Other unique subject populations include Ironman triathletes ${ }^{41}$, post-menopausal women ${ }^{29}$, and individuals living in specific geographical regions ${ }^{31,39}$. While studies in specific populations help to expand the description of prevalences, it can be challenging to reconcile the reported prevalences among the various studies.

The clinical imaging modality that is used to assess the rotator cuff (i.e., magnetic resonance imaging [MRI] or ultrasonography) also may influence the reported prevalence of RCTs. Although several studies have described the diagnostic accuracy of ultrasonography and MRI ${ }^{18,42,43}$, the precision with which these modalities can differentiate the various stages of pathology varies. For example, some studies that utilized ultrasonography reported the prevalence of only full-thickness RCTs and acknowledged a limited ability to identify partial-thickness tears ${ }^{26,28,35,39}$. Given that the diagnostic accuracy of both MRI and ultrasonography depends on the quality of the images, advances in imaging technology over 
the time period of the studies that are included in this review also could help to explain the variability of prevalence. Furthermore, studies often used different or unspecified criteria for how the presence, absence, or severity of an RCT was identified.

Collectively, these previous studies indicate that asymptomatic RCTs are prevalent in the general population (Table I), that the risk of asymptomatic RCTs increases with age $\mathrm{e}^{1,26,28,31,32,34,35,38,39}$, and that there is a high likelihood that patients who are being treated for shoulder pain or an RCT have an asymptomatic tear in the contralateral shoulder ${ }^{10,33,37,40}$. Advances in clinical imaging technology over the past 30 to 40 years have markedly improved the precision with which the various stages of rotator cuff pathology can be discriminated, and more recent studies have tended to report a lower prevalence than older studies. However, asymptomatic RCTs remain a common finding.

\section{Characteristics of Individuals with Asymptomatic RCTs}

\section{Patient-Reported Outcomes}

Several studies have compared subjective measures of shoulder function (i.e., patientreported outcomes) between individuals with an asymptomatic RCT and control subjects with an intact rotator cuff. However, the results often are conflicting. For example, compared with individuals with an intact rotator cuff, individuals with an asymptomatic RCT have reported a lower total Constant score ${ }^{28}$, a lower Simple Shoulder Test (SST) score ${ }^{44}$, and a lower reported ability to lift $3.6 \mathrm{~kg}(8 \mathrm{lb})$ to shoulder level ${ }^{44}$. In contrast, other studies have reported no significant difference in patient-reported outcomes of function between individuals with an intact rotator cuff and those with an asymptomatic $\mathrm{RCT}^{20,26,28,45}$. For example, Moosmayer et al. reported small but not significant differences in the American Shoulder and Elbow Surgeons (ASES) shoulder score between individuals with an intact rotator cuff and those with an asymptomatic full-thickness $\mathrm{RCT}^{26}$. Baumer et al. also failed to detect any significant difference in the Western Ontario Rotator Cuff (WORC) scores between similar subject populations ${ }^{20}$. Keener et al. reported that individuals with an asymptomatic RCT had lower ASES and SST scores than those with an intact rotator cuff, but concluded that the differences were "not clinically relevant." 45 These conflicting reports suggest that asymptomatic RCTs may not substantially impact shoulder function. However, the patient-reported functional outcomes may be confounded by the status of the contralateral shoulder and other upper-extremity joints. Furthermore, if functional deficits do in fact exist in individuals with asymptomatic RCTs, the conflicting results of these studies suggest that conventional patient-reported outcomes (e.g., WORC, ASES, Constant, and SST scores) may not have sufficient precision to reliably detect these differences. As such, conventional patient-reported outcomes alone may have limited use in helping to identify asymptomatic RCTs.

\section{Shoulder Strength}

Several studies have compared shoulder strength between individuals with an asymptomatic RCT and those with an intact rotator cuff ${ }^{9}, 20,26,28,32,45$. Some studies have reported deficits in shoulder strength in individuals with an asymptomatic RCT, but the findings have been inconsistent. For example, Kim et al. reported that the ratio of abduction strength to external 
rotation strength was lower in individuals with a full-thickness $\mathrm{RCT}^{32}$. In particular, decreased abduction strength was especially pronounced in individuals with a large or massive full-thickness RCT. Additionally, it has been reported that individuals with an asymptomatic RCT have lower elevation (i.e., flexion and/or abduction) strength compared with individuals with an intact rotator cuff $20,26,28$. Similarly, Yamamoto et al. reported that $17 \%$ of individuals with an asymptomatic RCT had weakness in abduction, while $12 \%$ had weakness in external rotation ${ }^{9}$. In contrast, several studies have reported no difference in external rotation or abduction strength between individuals with an asymptomatic RCT and control subjects with an intact rotator cuff $15,26,45$. Collectively, these findings suggest that measures of shoulder strength may not be substantially altered in the presence of an asymptomatic RCT; therefore, strength may not be the most reliable predictor of rotator cuff integrity.

The inconsistent findings regarding shoulder strength may be due to factors such as measurement methods and RCT morphology. Strength was generally assessed using a handheld dynamometer, and it is possible that isokinetic devices (e.g., from Biodex or Baltimore Therapeutic Equipment) may provide a more controlled and therefore sensitive assessment. This premise is supported by the findings of Baumer et al. ${ }^{20}$; with use of a Biodex device, they found reduced strength in individuals with asymptomatic RCTs. Additionally, RCT morphology may impact shoulder strength. Specifically, larger RCTs appear to result in larger reductions in shoulder strength ${ }^{32,35}$, and the results of cadaveric studies suggest that cable involvement may impact load transfer and, therefore, strength ${ }^{46,47}$.

\section{Range of Motion}

Similar to measures of shoulder strength, previous research has not reached a consensus regarding how asymptomatic RCTs influence gross shoulder range of motion. Kelly et al. reported that individuals with an asymptomatic RCT had approximately $6^{\circ}$ less scapularplane elevation than individuals without rotator cuff pathology 48 . In contrast, it has been reported that individuals with an asymptomatic RCT have greater forward elevation and external rotation range of motion than healthy control subjects ${ }^{45}$. However, for both studies, the magnitude of these reported range-of-motion differences was no more than approximately $5^{\circ}$ to $10^{\circ}$, so it is unclear if these differences are clinically meaningful. Not surprisingly, several studies have reported no difference in internal rotation, external rotation, abduction, and elevation range of motion between individuals with an intact rotator cuff and those with an asymptomatic $\mathrm{RCT}^{20,26,45,49}$. Clearly, the relationship between asymptomatic rotator cuff pathology and gross shoulder range of motion is not yet fully understood.

\section{Joint Kinematics}

Studies investigating differences in joint kinematics that are associated with asymptomatic RCTs have reported inconsistent findings, but some of these inconsistencies may be attributable to the specific measurement method. Studies that have relied on 2-dimensional static radiographs have reported mixed findings in proximal humeral migration (i.e., superior/inferior position or translation of the humerus relative to the glenoid) when comparing individuals with an asymptomatic RCT to those with an intact rotator cuff ${ }^{15,40,50}$. 
For example, Yamaguchi et al. reported that individuals with RCTs, regardless of symptom status, had significantly increased superior migration ${ }^{50}$. Specifically, the humerus of individuals with RCTs tended to migrate superiorly during shoulder elevation, whereas in individuals with an intact rotator cuff, the humerus tended to migrate inferiorly. Similarly, Keener et al. reported greater superior migration of the humerus with asymptomatic RCTs that involved the supraspinatus and infraspinatus (or infraspinatus only) (mean and standard deviation [SD], $0.5 \pm 1.0 \mathrm{~mm}$ ) compared with tears that involved the supraspinatus only (mean and $\mathrm{SD},-0.4 \pm 1.3 \mathrm{~mm}$ ) ${ }^{40}$. However, the mean difference in superior humeral migration between these 2 subject groups was $<1 \mathrm{~mm}$, which may be within the measurement uncertainty of this technique ${ }^{40}$. In contrast, Kijima et al. measured joint motion with dynamic fluoroscopy and reported no difference in kinematics between individuals with an intact rotator cuff and individuals with an asymptomatic tear ${ }^{49}$. However, this lack of difference in joint kinematics was likely due, at least in part, to a small sample size and relatively high variability between the subjects.

More recent work investigating glenohumeral kinematics in individuals with asymptomatic rotator cuff pathology has been performed with high accuracy using a biplane radiographic system $^{51}$. Baumer et al. performed a dynamic analysis of in vivo joint kinematics and reported that the humerus of individuals with asymptomatic rotator cuff pathology was positioned more inferiorly on the glenoid compared with control subjects with an intact rotator cuff ${ }^{20}$. Although this finding seems difficult to reconcile with the clinical dogma that the humerus appears high on the glenoid on conventional static radiographs, the finding may reflect differences in joint mechanics under static and dynamic conditions. The authors also reported that individuals with asymptomatic rotator cuff pathology had a longer path of glenohumeral joint contact, which may indicate that subtle deficits in muscle function are associated with asymptomatic rotator cuff pathology.

\section{Muscle Activity Patterns}

There appears to be relatively little information available on muscle activity patterns in individuals with an asymptomatic RCT. Kelly et al. conducted electromyography (EMG) analysis on individuals with an intact rotator cuff, patients with an asymptomatic RCT, and patients with a symptomatic tear. The study generally reported increased supraspinatus EMG activity in both symptomatic and asymptomatic individuals with an RCT compared with control subjects 48 .

\section{Summary}

In summary, studies have largely reported inconsistent findings regarding patient-reported outcomes, strength, range of motion, and kinematics in individuals with asymptomatic RCTs. Consequently, the extent to which an asymptomatic RCT impacts shoulder function remains unclear. If an asymptomatic RCT does indeed alter shoulder function, it appears that conventional clinical assessment tools may not have the necessary sensitivity to detect these alterations and, therefore, may be of limited diagnostic value when used in isolation. 


\section{Natural History of Asymptomatic RCTs}

Several studies have documented the natural history of asymptomatic RCTs by longitudinally assessing tissue characteristics (e.g., tear size) using ultrasonography, objective measures of shoulder function (e.g., strength), patient-reported outcomes, and symptom status ${ }^{13-17,52}$. Most of these studies followed individuals with confirmed fullthickness tears ${ }^{13,16,17}$, citing the ability of ultrasonography to measure tear characteristics more accurately in full-thickness tears compared with partial-thickness tears. However, 2 ultrasound studies followed individuals with partial-thickness tears ${ }^{14,15}$. Collectively, these studies provide useful information regarding risk factors for tear enlargement, symptom development, and functional decline. Although some natural history studies included individuals with a symptomatic contralateral shoulder ${ }^{13,15,53}$, their conclusions are not substantially different from other studies involving individuals without contralateral shoulder pain $^{16}$.

\section{Risk of Enlargement}

Enlargement of asymptomatic RCTs is common and typically observed within 3 years of tear identification ${ }^{13,14,16,17}$. Compared with partial-thickness tears, full-thickness tears tended to be at higher risk for enlargement over time $\left(\mathrm{p}=0.07\right.$, hazard ratio [HR]: 1.53) ${ }^{14}$. In particular, studies have reported that $38 \%$ to $61 \%$ of individuals with full-thickness asymptomatic tears ${ }^{13,16,17}$ and $44 \%$ of individuals with partial-thickness tears ${ }^{14}$ experienced enlargement within 3 years from the beginning of observation. However, without knowing the duration of time between the onset of the tear and the beginning of the observation period, the rate of tear progression is difficult to determine.

Previous studies also have reported the impact of various factors on the risk of tear enlargement, including shoulder dominance, physical activity, rotator cuff cable involvement, and the extent of muscle degeneration. Specifically, RCTs in the dominant shoulder are at a higher risk for enlargement ${ }^{14,53}$. However, a higher level of shoulder activity does not appear to be associated with a higher risk of enlargement ${ }^{53}$. Furthermore, tears involving the rotator cuff cable tend to have a higher frequency of enlargement than cable-intact tears $(\mathrm{p}=0.09 ; 67 \% \text { versus } 52 \% \text {, respectively })^{13}$. However, this finding may be confounded by cable-disrupted tears that are larger at baseline than cable-intact tears. Thus, it is difficult to know whether the higher risk of enlargement in cable-disrupted tears reflects a deficit in the theorized stress-shielding function of the cable or if cable-disrupted tears were simply more chronic at the onset of observation and more likely to progress. Additionally, supraspinatus muscle degeneration has been reported to influence the risk of tear enlargement, even in small tears ${ }^{14}$. In contrast, age, sex, and smoking status have not been found to be significantly associated with tear progression ${ }^{14}$.

\section{Development of Pain}

The eventual development of pain is common in individuals with a documented partialthickness or full-thickness RCT. Specifically, $23 \%$ to $51 \%$ of individuals with an initially asymptomatic RCT become symptomatic, typically within 1.5 to 3.0 years from the beginning of the observation period ${ }^{14-17}$. However, it is currently impossible to know when 
a degenerative RCT begins, making both chronicity and long-term survivorship unclear. Nevertheless, individuals whose shoulder became symptomatic were more likely to have tear enlargement than those who remained asymptomatic ${ }^{14-16}$. In particular, an enlargement of tear width appears to be more strongly related to the development of symptoms than an enlargement of tear retraction ${ }^{15,16}$. However, $37 \%$ to $77 \%$ of individuals who developed symptoms did not have significant enlargement ${ }^{14-17}$, suggesting that the alterations in tear characteristics cannot fully explain symptom development. These findings further emphasize that symptom development in the presence of an RCT is a complex and multifactorial process that is not yet fully understood.

The development of shoulder pain in the presence of a previously asymptomatic RCT has been associated with a decline in patient-reported function ${ }^{14-17}$. In general, individuals who became symptomatic had reduced shoulder flexion and/or abduction range of motion compared with those who remained asymptomatic ${ }^{14-16}$. A decline in internal and/or external rotation range of motion was less consistently observed, with some studies reporting a reduction ${ }^{14,15}$ and others showing no difference ${ }^{16}$.

\section{Summary}

Collectively, these natural history studies suggest that asymptomatic RCTs are likely to become symptomatic over time ${ }^{14-17}$; also, as individuals become symptomatic, they typically report worse patient-reported outcome scores ${ }^{14-17}$. In addition, RCTs that become symptomatic may be associated with functional deficits such as decreased strength ${ }^{14,16}$ and range of motion ${ }^{14-16}$, but alterations in glenohumeral or scapulothoracic kinematics may be subtle and/or not detectable ${ }^{16}$.

\section{Opportunities for Future Research}

This literature review has summarized the relatively few but valuable studies that have investigated asymptomatic rotator cuff pathology. Although much has been learned, many questions remain that require more research to improve the management of rotator cuff pathology across the spectrums of tissue integrity and symptom status. As previously suggested, an alternative strategy for dealing with this long-standing clinical problem may be to identify rotator cuff pathology while it is asymptomatic and then initiate exercises designed to maintain acceptable shoulder function and prevent the pathology from becoming symptomatic. To that end, this approach provides a number of opportunities for future research.

First, future research should fully characterize any functional alteration that is associated with asymptomatic rotator cuff pathology. Previous research efforts have identified some alteration in strength, kinematics, and range of motion that are associated with asymptomatic rotator cuff pathology, but these findings collectively have been largely inconclusive.

However, it remains plausible that asymptomatic rotator cuff pathology would be manifested through specific functional alterations, and, therefore, future efforts should identify the testing conditions and measurement techniques that are required to consistently elicit these alterations. It may be that identifying functional alterations that are associated with asymptomatic rotator cuff pathology requires shoulder function to be measured with greater 
accuracy and/or under more challenging testing conditions than what has been done previously. Alternatively, it is possible that unconventional measures of strength, kinematics, or range of motion may be necessary in order to differentiate individuals with asymptomatic rotator cuff pathology from those with a healthy intact rotator cuff. For example, perhaps descriptions of joint motion (i.e., displacement) may be more sensitive to differences than absolute joint positions. Future research should rigorously identify the testing methods, conditions, and outcomes that are required to identify individuals with asymptomatic rotator cuff pathology.

Second, if asymptomatic rotator cuff pathology can be linked to specific functional alterations, then future research should determine whether the alterations are detrimental or compensatory. For example, there is evidence to suggest that RCTs are associated with altered scapular motion in the form of increased upward rotation ${ }^{54-56}$. However, this finding does not necessarily imply that increased scapular upward rotation is an appropriate target for intervention because it may be a compensatory strategy for maintaining humerothoracic elevation because of decreased glenohumeral elevation. Consequently, future efforts should seek to correctly identify the targets that are most appropriate for early clinical intervention. For example, superior glenohumeral migration is thought to be detrimental for shoulder health but could be the result of insufficient rotator cuff muscle function (e.g., due to reduced strength and/or impaired motor control) or restricted glenohumeral joint mobility (e.g., due to glenohumeral osteoarthritis). Despite the same functional alteration (superior humeral head migration), clinical interventions (strengthening versus motor control training versus joint mobilization) could be disparate depending on the underlying cause. Finally, future studies should assess the extent to which early clinical intervention for the management of RCTs improves the long-term outcomes.

Third, future research efforts should focus on understanding the etiological factors that underlie rotator cuff pathology because the efficacy of early clinical intervention is likely dependent on this knowledge. Given that overuse is thought to be an important factor in the etiology of RCTs, concern may arise whether early exercise intervention is appropriate. This premise is supported by higher rates of tear progression and/or symptom development in dominant shoulders with asymptomatic RCTs ${ }^{14,15,53}$. However, shoulder activity level does not appear to be a predictor of tear enlargement ${ }^{53,57,58}$. This suggests that an RCT should not necessarily preclude an individual from performing exercise. However, more research is clearly needed to better understand the etiology of RCTs.

Fourth, future research efforts should focus on understanding the pain mechanisms that are associated with RCTs. Given the prevalence of asymptomatic RCTs, it is possible that other structures (e.g., subacromial bursa, biceps tendon) serve as the primary pain generators in symptomatic individuals. Furthermore, the prevalence of asymptomatic RCTs suggests that the nociceptive theory of pain cannot fully explain the relationship between pain and pathology. An alternative pain theory, central sensitization, suggests that pain may be mediated by central (i.e., neurological) mechanisms in addition to or independent from mechanical stimuli. Evidence of central sensitization has been found in individuals with shoulder pain ${ }^{59-61}$. Additionally, clinical practice would benefit from research into the role of genetic and biopsychosocial factors in an individual's pain experience. 
Fifth, the influence of RCT morphology (e.g., size, location, and cable involvement) and concomitant conditions (e.g., glenohumeral osteoarthritis) on factors such as shoulder strength, range of motion, and patient-reported outcomes is another opportunity for future research. The results of this research might help to identify individuals who are most susceptible to declining shoulder function and, therefore, most appropriate for early intervention.

Another intriguing opportunity for future research is developing and validating a homebased test for detecting asymptomatic rotator cuff pathology. A number of previous studies have described tests of upper-extremity function, and these tests are typically scored by documenting the time that is required for an individual to complete a standardized activity $^{62-67}$. While some of these tests have been shown to discriminate between healthy control subjects and patients with shoulder pain, it is unknown whether the tests can discriminate between asymptomatic individuals with intact rotator cuffs and those with torn rotator cuffs. Consequently, future research efforts should assess the extent to which existing functional tests can identify individuals with asymptomatic rotator cuff pathology or should develop and rigorously validate new functional tests.

\section{Overview}

Compared with symptomatic RCTs, relatively few studies have investigated asymptomatic rotator cuff pathology. The studies described herein indicate that asymptomatic RCTs are common, their prevalence increases with age, and there is a high likelihood that patients who are being treated for shoulder pain or an RCT have an asymptomatic tear in their contralateral shoulder. Unfortunately, conventional patient-reported outcomes (e.g., WORC or ASES scores) likely do not have sufficient precision to reliably identify the presence of an asymptomatic RCT. Similarly, functional measures (specifically, measures of strength, joint motion, and range of motion) and EMG also appear to have a limited ability to discriminate between individuals with an asymptomatic RCT and those with a healthy intact rotator cuff. Asymptomatic RCTs are likely to enlarge over the course of several years, but the development of symptoms is not understood.

An alternative approach to the long-standing clinical issue of rotator cuff pathology could involve identifying pathology (perhaps through a home-based test of shoulder function) when an individual is asymptomatic and then intervening with exercises that are designed to ensure that an asymptomatic RCT remains asymptomatic while maintaining the individual's shoulder function. If a home-based test was available that reliably identified the presence of asymptomatic rotator cuff pathology, then it is possible that early intervention could help to avoid the clinical sequelae that begin with symptom development and end with compromised shoulder function after surgical repair. Large-scale implementation of this approach could substantially reduce the number of patients seeking conventional clinical intervention for symptomatic rotator cuff pathology. However, development and validation of this proposed approach will require considerable research efforts.

\section{Acknowledgments}

Disclosure: The authors indicated that no external funding was received for any aspect of this work. 


\section{References}

1. Milgrom C, Schaffler M, Gilbert S, van Holsbeeck M. Rotator-cuff changes in asymptomatic adults. The effect of age, hand dominance and gender. J Bone Joint Surg Br. 1995 3;77(2):296-8. [PubMed: 7706351]

2. Kim HM, Dahiya N, Teefey SA, Middleton WD, Stobbs G, Steger-May K, Yamaguchi K, Keener JD. Location and initiation of degenerative rotator cuff tears: an analysis of three hundred and sixty shoulders. J Bone Joint Surg Am. 2010 5;92(5):1088-96. [PubMed: 20439653]

3. Yamamoto A, Takagishi K, Osawa T, Yanagawa T, Nakajima D, Shitara H, Kobayashi T. Prevalence and risk factors of a rotator cuff tear in the general population. J Shoulder Elbow Surg. 2010 1;19(1):116-20. [PubMed: 19540777]

4. Smith KL, Harryman DT 2nd, Antoniou J, Campbell B, Sidles JA, Matsen FA 3rd. A prospective, multipractice study of shoulder function and health status in patients with documented rotator cuff tears. J Shoulder Elbow Surg. 2000 Sep-Oct;9(5):395-402. [PubMed: 11075323]

5. Gartsman GM, Brinker MR, Khan M, Karahan M. Self-assessment of general health status in patients with five common shoulder conditions. J Shoulder Elbow Surg. 1998 May-Jun;7(3):22837. [PubMed: 9658347]

6. Colvin AC, Egorova N, Harrison AK, Moskowitz A, Flatow EL. National trends in rotator cuff repair. J Bone Joint Surg Am. 20122 1;94(3):227-33. [PubMed: 22298054]

7. Silverstein B, Kalat J. Work-related musculoskeletal disorders of the neck, back, and upper extremity in Washington State, 1992-2000. Technical report no 40-6-2002. 2002.

8. Vitale MA, Vitale MG, Zivin JG, Braman JP, Bigliani LU, Flatow EL. Rotator cuff repair: an analysis of utility scores and cost-effectiveness. J Shoulder Elbow Surg. 2007 Mar-Apr;16(2): 1817. [PubMed: 17399623]

9. Yamamoto A, Takagishi K, Kobayashi T, Shitara H, Osawa T. Factors involved in the presence of symptoms associated with rotator cuff tears: a comparison of asymptomatic and symptomatic rotator cuff tears in the general population. J Shoulder Elbow Surg. 2011 10; 20(7):1133-7. Epub 2011 Mar 30. [PubMed: 21454096]

10. Liem D, Buschmann VE, Schmidt C, Gosheger G, Vogler T, Schulte TL, Balke M. The prevalence of rotator cuff tears: is the contralateral shoulder at risk? Am J Sports Med. 2014 4;42(4):826-30. Epub 2014 Feb 5. [PubMed: 24500916]

11. Gumina S, Candela V, Passaretti D, Latino G, Venditto T, Mariani L, Santilli V. The association between body fat and rotator cuff tear: the influence on rotator cuff tear sizes. J Shoulder Elbow Surg. 2014 11;23(11):1669-74. Epub 2014 Jun 4. [PubMed: 24906904]

12. Baumgarten KM, Gerlach D, Galatz LM, Teefey SA, Middleton WD, Ditsios K, Yamaguchi K. Cigarette smoking increases the risk for rotator cuff tears. Clin Orthop Relat Res. 2010 6;468(6): 1534-41. Epub 2009 Mar 13. [PubMed: 19283436]

13. Keener JD, Hsu JE, Steger-May K, Teefey SA, Chamberlain AM, Yamaguchi K. Patterns of tear progression for asymptomatic degenerative rotator cuff tears. J Shoulder Elbow Surg. 2015 12;24(12):1845-51. [PubMed: 26589385]

14. Keener JD, Galatz LM, Teefey SA, Middleton WD, Steger-May K, Stobbs-Cucchi G, Patton R, Yamaguchi K. A prospective evaluation of survivorship of asymptomatic degenerative rotator cuff tears. J Bone Joint Surg Am. 20151 21;97(2):89-98. [PubMed: 25609434]

15. Mall NA, Kim HM, Keener JD, Steger-May K, Teefey SA, Middleton WD, Stobbs G, Yamaguchi K. Symptomatic progression of asymptomatic rotator cuff tears: a prospective study of clinical and sonographic variables. J Bone Joint Surg Am. 201011 17;92(16):2623-33. [PubMed: 21084574]

16. Moosmayer S, Tariq R, Stiris M, Smith HJ. The natural history of asymptomatic rotator cuff tears: a three-year follow-up of fifty cases. J Bone Joint Surg Am. 20137 17;95(14):1249-55. [PubMed: 23864172]

17. Yamaguchi K, Tetro AM, Blam O, Evanoff BA, Teefey SA, Middleton WD. Natural history of asymptomatic rotator cuff tears: a longitudinal analysis of asymptomatic tears detected sonographically. J Shoulder Elbow Surg. 2001 May-Jun;10(3):199-203. [PubMed: 11408898]

18. Lenza M, Buchbinder R, Takwoingi Y, Johnston RV, Hanchard NC, Faloppa F. Magnetic resonance imaging, magnetic resonance arthrography and ultrasonography for assessing rotator cuff tears in 
people with shoulder pain for whom surgery is being considered. Cochrane Database Syst Rev. 2013 9 24;9:CD009020.

19. Kuhn JE, Dunn WR, Sanders R, An Q, Baumgarten KM, Bishop JY, Brophy RH, Carey JL, Holloway BG, Jones GL, Ma CB, Marx RG, McCarty EC, Poddar SK, Smith MV, Spencer EE, Vidal AF, Wolf BR, Wright RW; MOON Shoulder Group. Effectiveness of physical therapy in treating atraumatic full-thickness rotator cuff tears: a multicenter prospective cohort study. J Shoulder Elbow Surg. 2013 10;22(10):1371-9. Epub 2013 Mar 27. [PubMed: 23540577]

20. Baumer TG, Dischler J, Mende V, Zauel R, van Holsbeeck M, Siegal DS, Divine G, Moutzouros V, Bey MJ. Effects of asymptomatic rotator cuff pathology on in vivo shoulder motion and clinical outcomes. J Shoulder Elbow Surg. 20176;26(6):1064-72.Epub 2017 Jan 25. [PubMed: 28131679]

21. Miller RM, Popchak A, Vyas D, Tashman S, Irrgang JJ, Musahl V, Debski RE. Effects of exercise therapy for the treatment of symptomatic full-thickness supraspinatus tears on in vivo glenohumeral kinematics. J Shoulder Elbow Surg. 2016 4;25(4):641-9. Epub 2015 Nov 24. [PubMed: 26620280]

22. MacDonald P, McRae S, Leiter J, Mascarenhas R, Lapner P. Arthroscopic rotator cuff repair with and without acromioplasty in the treatment of full-thickness rotator cuff tears: a multicenter, randomized controlled trial. J Bone Joint Surg Am. 201111 2;93(21): 1953-60. [PubMed: 22048089]

23. Ma HL, Chiang ER, Wu HT, Hung SC, Wang ST, Liu CL, Chen TH. Clinical outcome and imaging of arthroscopic single-row and double-row rotator cuff repair: a prospective randomized trial. Arthroscopy. 2012 1;28(1): 16-24. Epub 2011 Oct 7. [PubMed: 21982391]

24. Abrams GD, Gupta AK, Hussey KE, Tetteh ES, Karas V, Bach BR Jr, Cole BJ, Romeo AA, Verma NN. Arthroscopic repair of full-thickness rotator cuff tears with and without acromioplasty: randomized prospective trial with 2-year follow-up. Am J Sports Med. 2014 6;42(6): 1296-303. Epub 2014 Apr 14. [PubMed: 24733157]

25. McElvany MD, McGoldrick E, Gee AO, Neradilek MB, Matsen FA 3rd. Rotator cuff repair: published evidence on factors associated with repair integrity and clinical outcome. Am J Sports Med. 2015 2;43(2): 491-500. Epub 2014 Apr 21. [PubMed: 24753240]

26. Moosmayer S, Smith HJ, Tariq R, Larmo A. Prevalence and characteristics of asymptomatic tears of the rotator cuff: an ultrasonographic and clinical study. J Bone Joint Surg Br. 2009 2;91(2):196200. [PubMed: 19190053]

27. Moosmayer S, Tariq R, Stiris MG, Smith HJ. MRI of symptomatic and asymptomatic fullthickness rotator cuff tears. A comparison of findings in 100 subjects. Acta Orthop. 2010 6; 81(3): 361-6. [PubMed: 20450423]

28. Schibany N, Zehetgruber H, Kainberger F, Wurnig C, Ba-Ssalamah A, Herneth AM, Lang T, Gruber D, Breitenseher MJ. Rotator cuff tears in asymptomatic individuals: a clinical and ultrasonographic screening study. Eur J Radiol. 2004 9;51(3):263-8. [PubMed: 15294335]

29. Abate M, Schiavone C, Di Carlo L, Salini V. Prevalence of and risk factors for asymptomatic rotator cuff tears in postmenopausal women. Menopause. 2014 3;21(3):275-80. [PubMed: 23760436]

30. Girish G, Lobo LG, Jacobson JA, Morag Y, Miller B, Jamadar DA. Ultrasound of the shoulder: asymptomatic findings in men. AJR Am J Roentgenol. 2011 10;197(4):W713-9. [PubMed: 21940544]

31. Jeong J, Shin DC, Kim TH, Kim K. Prevalence of asymptomatic rotator cuff tear and their related factors in the Korean population. J Shoulder Elbow Surg. 2017 1;26(1):30-5. Epub 2016 Aug 3. [PubMed: 27497789]

32. Kim HM, Teefey SA, Zelig A, Galatz LM, Keener JD, Yamaguchi K. Shoulder strength in asymptomatic individuals with intact compared with torn rotator cuffs. J Bone Joint Surg Am. 2009 2;91(2):289-96. [PubMed: 19181972]

33. Ro KH, Park JH, Lee SH, Song DI, Jeong HJ, Jeong WK. Status of the contralateral rotator cuff in patients undergoing rotator cuff repair. Am J Sports Med. 2015 5;43(5):1091-8. Epub 2015 Mar 4. [PubMed: 25740834] 
34. Sher JS, Uribe JW, Posada A, Murphy BJ, Zlatkin MB. Abnormal findings on magnetic resonance images of asymptomatic shoulders. J Bone Joint Surg Am. 1995 1; 77(1):10-5. [PubMed: 7822341]

35. Tempelhof S, Rupp S, Seil R. Age-related prevalence of rotator cuff tears in asymptomatic shoulders. J Shoulder Elbow Surg. 1999 Jul-Aug;8(4):296-9. [PubMed: 10471998]

36. Teunis T, Lubberts B, Reilly BT, Ring D. A systematic review and pooled analysis of the prevalence of rotator cuff disease with increasing age. J Shoulder Elbow Surg. 2014 12;23(12): 1913-21. [PubMed: 25441568]

37. Yamaguchi K, Ditsios K, Middleton WD, Hildebolt CF, Galatz LM, Teefey SA. The demographic and morphological features of rotator cuff disease. A comparison of asymptomatic and symptomatic shoulders. J Bone Joint Surg Am. 2006 8;88(8):1699-704. [PubMed: 16882890]

38. Needell SD, Zlatkin MB, Sher JS, Murphy BJ, Uribe JW. MR imaging of the rotator cuff: peritendinous and bone abnormalities in an asymptomatic population. AJR Am J Roentgenol. 1996 4;166(4):863-7. [PubMed: 8610564]

39. Minagawa H, Yamamoto N, Abe H, Fukuda M, Seki N, Kikuchi K, Kijima H, Itoi E. Prevalence of symptomatic and asymptomatic rotator cuff tears in the general population: from mass-screening in one village. J Orthop. 20132 26; 10(1):8-12. [PubMed: 24403741]

40. Keener JD, Wei AS, Kim HM, Steger-May K, Yamaguchi K. Proximal humeral migration in shoulders with symptomatic and asymptomatic rotator cuff tears. J Bone Joint Surg Am. 2009 6;91(6):1405-13. [PubMed: 19487518]

41. Reuter RM, Hiller WD, Ainge GR, Brown DW, Dierenfield L, Shellock FG, Crues JV 3rd. Ironman triathletes: MRI assessment of the shoulder. Skeletal Radiol. 2008 8;37(8): 737-41. Epub 2008 Jun 10. [PubMed: 18542952]

42. Teefey SA, Hasan SA, Middleton WD, Patel M, Wright RW, Yamaguchi K. Ultrasonography of the rotator cuff. A comparison of ultrasonographic and arthroscopic findings in one hundred consecutive cases. J Bone Joint Surg Am. 2000 4;82(4):498-504. [PubMed: 10761940]

43. Teefey SA, Rubin DA, Middleton WD, Hildebolt CF, Leibold RA, Yamaguchi K. Detection and quantification of rotator cuff tears. Comparison of ultrasonographic, magnetic resonance imaging, and arthroscopic findings in seventy-one consecutive cases. J Bone Joint Surg Am. 2004 4;86(4): 708-16. [PubMed: 15069134]

44. Nakajima D, Yamamoto A, Kobayashi T, Osawa T, Shitara H, Ichinose T, Takasawa E, Takagishi $\mathrm{K}$. The effects of rotator cuff tears, including shoulders without pain, on activities of daily living in the general population. J Orthop Sci. 2012 3;17(2):136-40. Epub 2012 Jan 17. [PubMed: 22249436]

45. Keener JD, Steger-May K, Stobbs G, Yamaguchi K. Asymptomatic rotator cuff tears: patient demographics and baseline shoulder function. J Shoulder Elbow Surg. 2010 12; 19(8):1191-8. Epub 2010 Oct 27. [PubMed: 21030274]

46. Halder AM, O’Driscoll SW, Heers G, Mura N, Zobitz ME, An KN, Kreusch-Brinker R. Biomechanical comparison of effects of supraspinatus tendon detachments, tendon defects, and muscle retractions. J Bone Joint Surg Am. 2002 5;84(5):780-5. [PubMed: 12004021]

47. Mesiha MM, Derwin KA, Sibole SC, Erdemir A, McCarron JA. The biomechanical relevance of anterior rotator cuff cable tears in a cadaveric shoulder model. J Bone Joint Surg Am. 201310 16;95(20):1817-24. [PubMed: 24132354]

48. Kelly BT, Williams RJ, Cordasco FA, Backus SI, Otis JC, Weiland DE, Altchek DW, Craig EV, Wickiewicz TL, Warren RF. Differential patterns of muscle activation in patients with symptomatic and asymptomatic rotator cuff tears. J Shoulder Elbow Surg. 2005 Mar-Apr; 14(2): 165-71. [PubMed: 15789010]

49. Kijima T, Matsuki K, Ochiai N, Yamaguchi T, Sasaki Y, Hashimoto E, Sasaki Y, Yamazaki H, Kenmoku T, Yamaguchi S, Masuda Y, Umekita H, Banks SA, Takahashi K. In vivo 3-dimensional analysis of scapular and glenohumeral kinematics: comparison of symptomatic or asymptomatic shoulders with rotator cuff tears and healthy shoulders. J Shoulder Elbow Surg. 2015 11;24(11): 1817-26. Epub 2015 Jul 30. [PubMed: 26234667] 
50. Yamaguchi K, Sher JS, Andersen WK, Garretson R, Uribe JW, Hechtman K, Neviaser RJ. Glenohumeral motion in patients with rotator cuff tears: a comparison of asymptomatic and symptomatic shoulders. J Shoulder Elbow Surg. 2000 Jan-Feb;9(1):6-11. [PubMed: 10717855]

51. Bey MJ, Zauel R, Brock SK, Tashman S. Validation of a new model-based tracking technique for measuring three-dimensional, in vivo glenohumeral joint kinematics. J Biomech Eng. 2006 8;128(4):604-9. [PubMed: 16813452]

52. Tashjian RZ. Epidemiology, natural history, and indications for treatment of rotator cuff tears. Clin Sports Med. 2012 10;31(4):589-604. Epub 2012 Aug 30. [PubMed: 23040548]

53. Keener JD, Skelley NW, Stobbs-Cucchi G, Steger-May K, Chamberlain AM, Aleem AW, Brophy RH. Shoulder activity level and progression of degenerative cuff disease. J Shoulder Elbow Surg. 2017 9;26(9):1500-7. Epub 2017 Jul 19. [PubMed: 28734718]

54. Mell AG, LaScalza S, Guffey P, Ray J, Maciejewski M, Carpenter JE, Hughes RE. Effect of rotator cuff pathology on shoulder rhythm. J Shoulder Elbow Surg. 2005 Jan-Feb;14(1)(Suppl S):58S64S. [PubMed: 15726088]

55. Paletta GA Jr, Warner JJ, Warren RF, Deutsch A, Altchek DW. Shoulder kinematics with two-plane $\mathrm{x}$-ray evaluation in patients with anterior instability or rotator cuff tearing. J Shoulder Elbow Surg. 1997 Nov-Dec;6(6):516-27. [PubMed: 9437601]

56. Kolk A, Henseler JF, de Witte PB, van Zwet EW, van der Zwaal P, Visser CPJ, Nagels J, Nelissen RGHH, de Groot JH. The effect of a rotator cuff tear and its size on three-dimensional shoulder motion. Clin Biomech (Bristol, Avon). 2017 6;45:43-51. Epub 2017 Apr 11.

57. Yamamoto N, Mineta M, Kawakami J, Sano H, Itoi E. Risk factors for tear progression in symptomatic rotator cuff tears: a prospective study of 174 shoulders. Am J Sports Med. 2017 9;45(11):2524-31. Epub 2017 Jun 13. [PubMed: 28609119]

58. Kim YS, Kim SE, Bae SH, Lee HJ, Jee WH, Park CK. Tear progression of symptomatic fullthickness and partial-thickness rotator cuff tears as measured by repeated MRI. Knee Surg Sports Traumatol Arthrosc. 2017 7;25(7): 2073-80. Epub 2016 Nov 30. [PubMed: 27904936]

59. Plinsinga ML, Brink MS, Vicenzino B, van Wilgen CP. Evidence of nervous system sensitization in commonly presenting and persistent painful tendinopathies: a systematic review. J Orthop Sports Phys Ther. 2015 11; 45(11):864-75. Epub 2015 Sep 21. [PubMed: 26390275]

60. Borstad J, Woeste C. The role of sensitization in musculoskeletal shoulder pain. Braz J Phys Ther. 2015 Jul-Aug;19(4):251-7. Epub 2015 Aug 7. [PubMed: 26443971]

61. Sanchis MN, Lluch E, Nijs J, Struyf F, Kangasperko M. The role of central sensitization in shoulder pain: a systematic literature review. Semin Arthritis Rheum. 2015 6;44(6):710-6. Epub 2014 Nov 13. [PubMed: 25523242]

62. de Oliveira VM, Pitangui AC, Nascimento VY, da Silva HA, Dos Passos MH, de Araújo RC. TestRetest reliability of the closed kinetic chain upper extremity stability test (CKCUEST) in adolescents: reliability of CKCUEST in adolescents. Int J Sports Phys Ther. 2017 2; 12(1):125-32. [PubMed: 28217423]

63. Kumta P, MacDermid JC, Mehta SP, Stratford PW. The FIT-HaNSA demonstrates reliability and convergent validity of functional performance in patients with shoulder disorders. J Orthop Sports Phys Ther. 2012 5;42(5): 455-64. Epub 2012 Jan 25. [PubMed: 22281818]

64. MacDermid JC, Ghobrial M, Quirion KB, St-Amour M, Tsui T, Humphreys D, McCluskie J, Shewayhat E, Galea V. Validation of a new test that assesses functional performance of the upper extremity and neck (FIT-HaNSA) in patients with shoulder pathology. BMC Musculoskelet Disord. 20075 17;8:42. [PubMed: 17509150]

65. Roy JS, Ma B, Macdermid JC, Woodhouse LJ. Shoulder muscle endurance: the development of a standardized and reliable protocol. Sports Med Arthrosc Rehabil Ther Technol. 2011 111;3(1):1. [PubMed: 21223588]

66. Shah KM, Baker T, Dingle A, Hansmeier T, Jimenez M, Lopez S, Marks D, Safford D, Sternberg A, Turner J, McClure PW. Early development and reliability of the timed Functional Arm and Shoulder Test. J Orthop Sports Phys Ther. 2017 6;47(6):420-31. Epub 2017 Mar 3. [PubMed: 28257615] 
67. Tucci HT, Martins J, Sposito Gde C, Camarini PM, de Oliveira AS. Closed kinetic chain upper extremity stability test (CKCUES test): a reliability study in persons with and without shoulder impingement syndrome. BMC Musculoskelet Disord. 2014 1 3;15:1. [PubMed: 24387196]

68. Worland RL, Lee D, Orozco CG. SozaRex F, Keenan J. Correlation of age, acromial morphology, and rotator cuff tear pathology diagnosed by ultrasound in asymptomatic patients. J South Orthop Assoc. 2003 Spring; 12(1):23-6. [PubMed: 12735621]

69. Miniaci A, Dowdy PA, Willits KR, Vellet AD. Magnetic resonance imaging evaluation of the rotator cuff tendons in the asymptomatic shoulder. Am J Sports Med. 1995 Mar-Apr;23(2): 142-5. [PubMed: 7778695]

70. Gill TK, Shanahan EM, Allison D, Alcorn D, Hill CL. Prevalence of abnormalities on shoulder MRI in symptomatic and asymptomatic older adults. Int J Rheum Dis. 2014 11;17(8):863-71. Epub 2014 Oct 8. [PubMed: 25294682] 


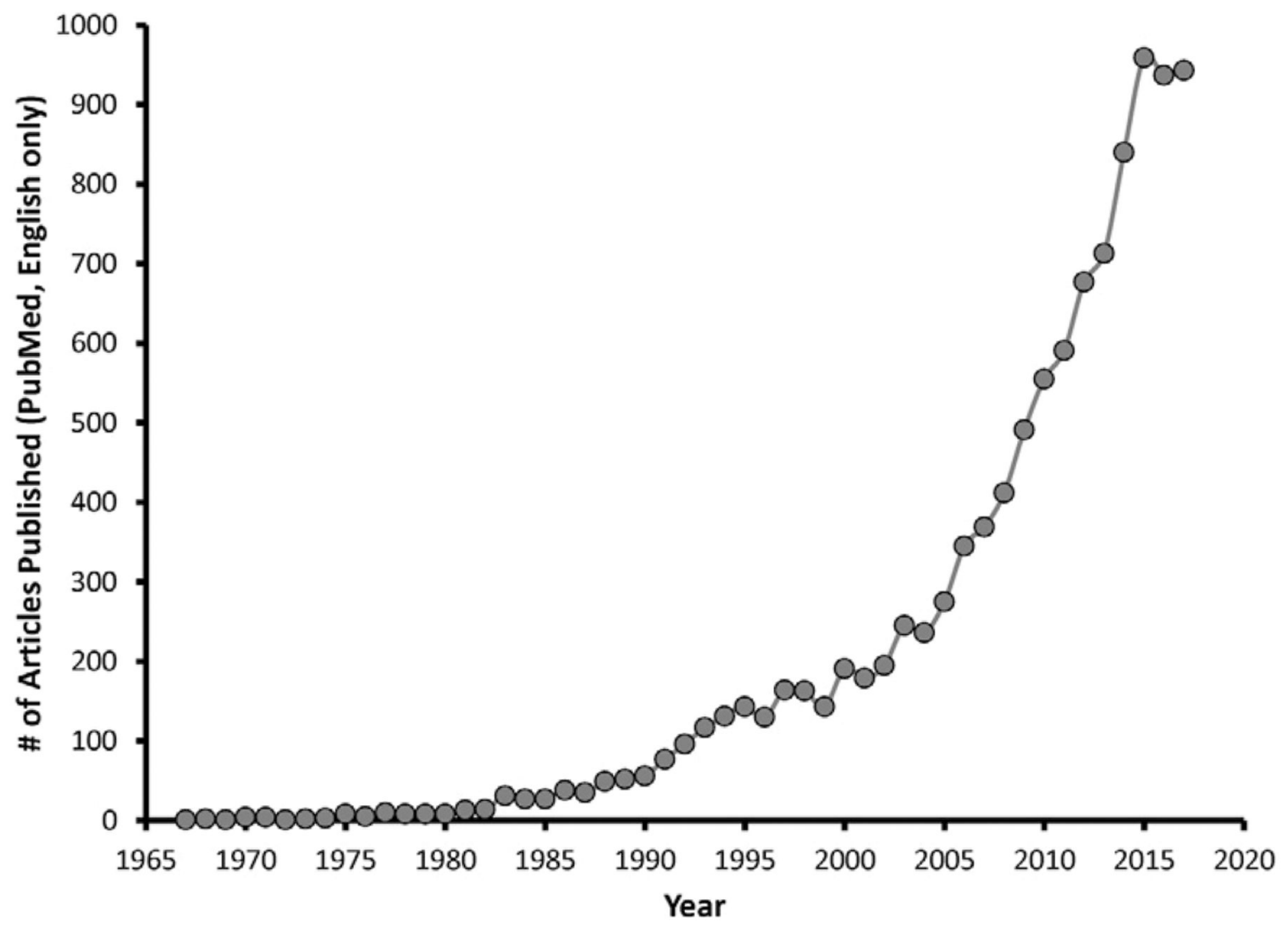

Fig. 1.

The number of published rotator cuff articles (PubMed search: "rotator cuff"; English language only) has risen dramatically over the past 50 years. 


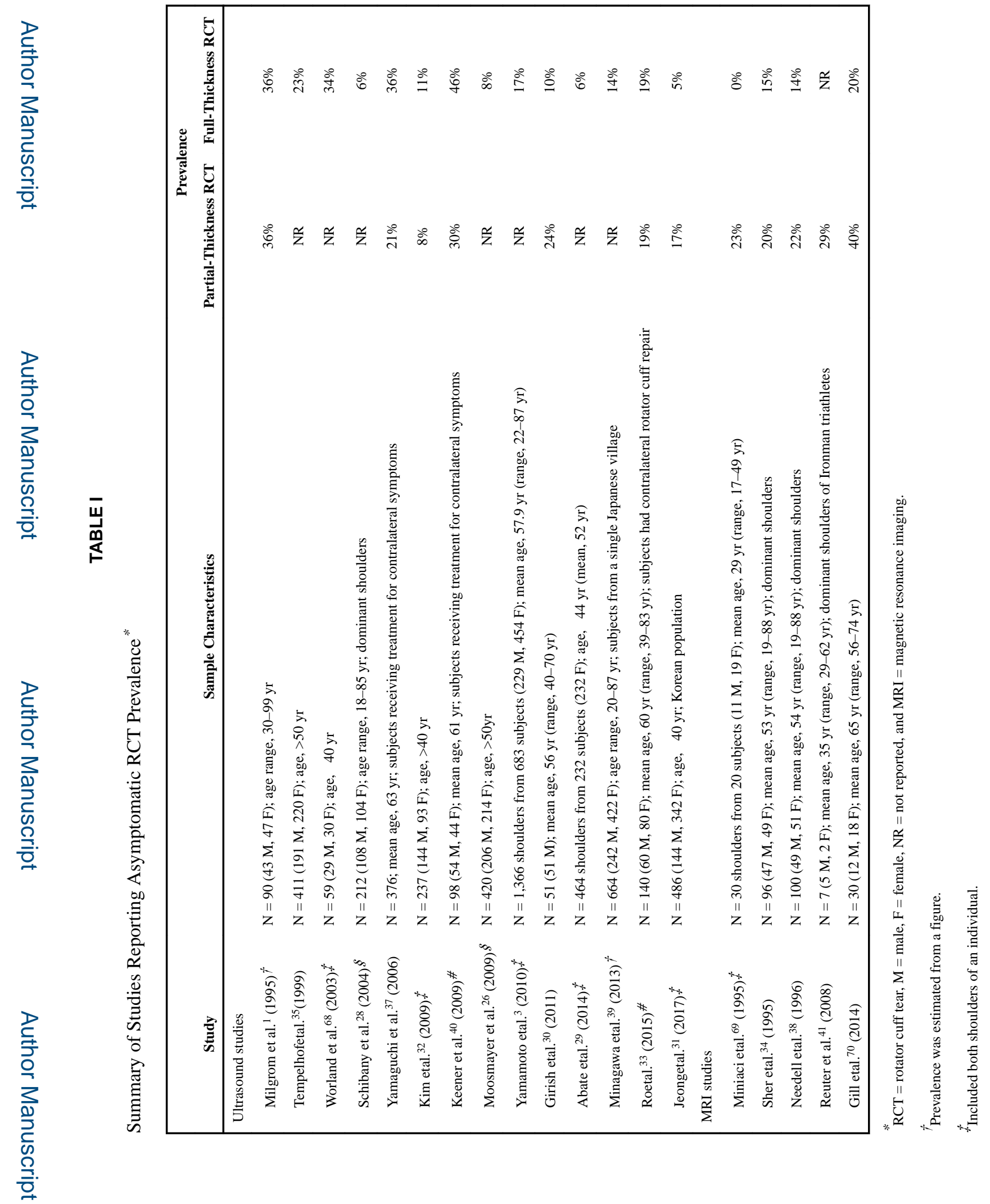

JBJS Rev. Author manuscript; available in PMC 2020 February 18. 


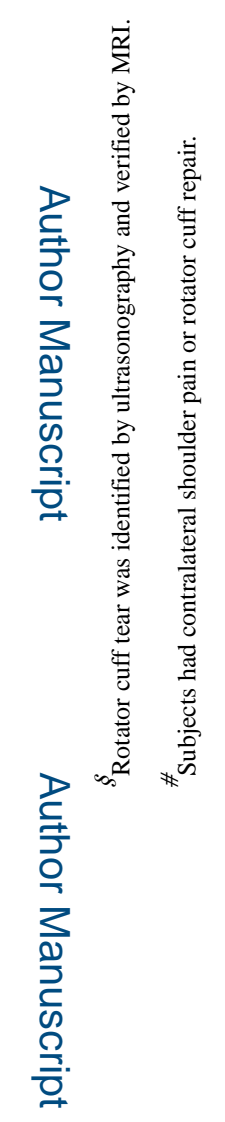

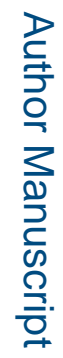

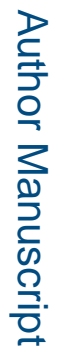

JBJS Rev. Author manuscript; available in PMC 2020 February 18. 